\title{
The Strategies of the Popularization of Mandarin Chinese in the Philippines under the New Sino- Philippine Relations
}

\author{
Lili Xu
}

The Southern Base of Confucius Institute Headquarters, Xiamen University

Xiamen, China

Lynch206@163.com

\author{
Dehui Li \\ College of Foreign language and Cultures, \\ Xiamen University \\ Xiamen, China \\ 740988347@qq.com
}

\begin{abstract}
At present, the popularization of Mandarin Chinese (PMC) in the Philippines are facing some problems, such as low effectiveness of class teaching, the obstruction from the mainstream society, fierce competition with other foreign languages. This article tries to provide some specific suggestions on the teaching subjects, contents, channels, and layout considering the analysis of the history and status quo of PMC in this area.
\end{abstract}

Keywords-Philippines; popularization of Mandarin Chinese; Sino-Philippine relations; diversification

\section{INTRODUCTION}

The Philippines is located in southeastern Asia and is an important neighbor of China. Sino-Philippine relations have warmed up since the end of 2016 when all-round cooperation have stepped into a new phase and provided a brand-new opportunity for the popularization of Mandarin Chinese (PMC) in the Philippines. Therefore, drawing on past achievements and experience to explore a new way for further PMC in the new situation will deepen the cultural interaction between the two countries and will contribute to the Sino-Philippine cooperation both in the economy and in other areas.

\section{The STATUS QUO OF PMC IN THE PhILIPPINES}

A. The revitalization of Chinese Language Education (CLE) and the innovation of Chinese Teaching Institutes and International Exchanges.)

One hundred and eighteen years has witnessed the development of CLE in the Philippines since the founding of Tiong Se Academy in Qing Dynasty, the first institute for overseas Chinese in 1899. Initiated by the 176 Act, issued by former Philippine Ferdinand Marcos in 1973 to indigenize all alien schools, CLE has experienced lots of twists and turns, from the founding stage (1899-1912), expansion phase (19121941), pause phase (1941-1945), resume phase (1945-1955), regulation phase (1955-1973) to transforming phase(19731991) ${ }^{1}$. According to the statistics of Philippines Comprehensive Education Yearbook of CLE (2004-2014),

${ }^{1}$ Philippine Chinese Education Research Center,

http://www.pcerc.org/Others/Develop/Develop.htm,2017-5-20 there are 167 Philippine Chinese schools(PCS), most of which have established courses from kindergarten to middle school.

Since the 1990s, conforming to the trend of times, PCS and CLE institutes have been exploring new methods on internal mechanism, teaching methodology and international exchanges, which brought in more students coming for schooling. "Students of Chinese descendants are not the only group in schools, the ratio of non-Chinese is still in the rise." ${ }^{2}$ On $10^{\text {th }}$ April 2016, the 2nd Summit Conference for the Philippine Chinese School hosted by the Tan Yankui Fund and the Center for Chinese Language Education in the Philippines was held in Manila. Representatives of 96 Chinese schools have come to a new resolution----Carrying Forward CLE Spirit and composing a new chapter of CLE on the status and purpose of PCS, the PCS model under new schooling system, the adoption of professional Chinese teachers, and the adoption of evaluation of teaching quality of PCS, which is striving for the more standard, scientific and practical direction. Meanwhile, the Philippine CLE institutes and PCS are active in international cooperation and exchanges, especially academic exchanges in professional teachers, management staff introduction, teaching and academic lectures with China's education department, and teaching institutes of all kinds as well as mutual exchange of students.

\section{B. More attention from the Authority with policy support.}

With the rapid development of China's economy and the higher economic value of Chinese in the international society, the officials of the Philippines are paying more attention to the popularization of Chinese at the mainstream society and implementing policy encouragement at the high education. In 2001, the Philippine High Education Committee (PHEC) signed a memo to all public and private high education institutes to enlist Chinese as a selective course for undergraduates and Ph. D candidates. In March 2003, PHEC and China Hanban signed Sino-Philippine Chinese Teaching Cooperation Memo. According to the Memo, assisted and coordinated by China Hanban, PHEC carried out series of

\footnotetext{
${ }^{2}$ Zheng Tongtao , Jiang Youjing and Chen Ronglan ,The Annual Report of Teaching Chinese as a Second Language in Southeast Asian(II)[J], Overseas Chinese Education, 2014(02):125.(In Chinese)
} 
activities including teacher training and established the Confucius Institute (CI) at Ateneo de Manila University, Bulacan State University, Angeles University Foundation and University of the Philippines from October 2006 to October 2015. The four CIs, founded on the basis of the advantages of high education resources of China and Philippines, make us of the professional teachers from China to open up specific courses for colleges, high schools and primary schools, government agencies, enterprises and social groups and further satisfy the Philippine demand for learning Chinese through local Chinese teacher training, teaching seminars, Chinese culture activities, HSK exams.

From 2013, the Philippine Education Ministry adopts the $\mathrm{K}-12$ educational system to replace the 10-year one, which enlists Chinese as a selective foreign language in the country's foreign language education. In February 2017, the Philippine Education Ministry announced that it would continue to carry out SPFL(Special Foreign Language) to select middle school students from grade 7 to 12 who have passed English proficiency test to learn one second foreign language (Spanish, Japanese, French, Chinese and Korean). The program was initiated in 2009-2010, which has enrolled as high as 10526 by February in 2017. Among them, $2280^{3}$ students are learning Chinese, accounting for $21.7 \%$. From those figures above, Chinese is popularized in the mainstream society.

\section{PRoblems Faced By the Popularization OF CHINESE IN THE PHILIPPINES}

\section{A. Influenced by state policies, social environment, teaching} style and teachers, the effectiveness of Chinese teaching is not as good as expected.

Recent years, the CLE in the Philippines is getting better with more excellent students. However, the whole teaching effect and the professionals with high proficiency in Chinese still have a large room to improve. Doctor ELLEN H.PALANCA pointed out the quality problem on comparing the Chinese education of Malaria and the Philippines. The most conspicuous example is that many students in PCS learning Chinese for 13 years are incapable of talk and read in Chinese. ${ }^{4}$ The direct reason is the restriction of the Philippine regulations and the deficiency of Chinese language. It regulates that the Philippine and Chinese could only be taught as selective courses with less than 120 minutes each day and the duration of Chinese courses in middle schools is shortened into four years. The new generations of Chinese descendants, born in the Philippines, are most times taken care of by the Philippine nurses called "yaya”, which may make Tagalog or local languages as their first language. While their parents have to learn to use Philippine as influent as possible to survive and do business. Those make Philippine the family language of local overseas Chinese. These invade the Chinese learning environment and disturb learning effect.

\footnotetext{
${ }^{3}$ Department to Education, Republic of The Philippines,

http://www.deped.gov.ph/press-releases/

deped-enhances-learners\%E2\%80\%99-foreign-language-skills-through-

special-program-foreign, 2017-5-20

${ }^{4}$ ELLEN H.PALANCA,A Comparative Study of Chinese Education in the

Philippines and Malaysia[J], ASIAN STUDIES 2002(11):3-4.
}

On the other hand, PCS are facing the dilemma of adaptation on teaching methods and faculty. For decades, in most PCS Chinese is taught in local languages when new teaching methods are under exploration. Obviously, it was hard for the Philippine-born Chinese descendants to accept being crammed Chinese vocabulary and grammar because they were lack of relevant language background and passion for Chinese cultural. Chinese teachers were usually incompetent to motivate students to learn for the absence of professional training skills for teachers. Although the Center for Chinese Teaching in the Philippines has launched "Blood Transfusion" and "Hematopoiesis Plan", there are still difficulties concerning the deficiency of Philippine cultural background, malfunction of intermediate language in teaching and the maintenance of young teachers having studied in China staying in faculty.

\section{B. Challenges and opportunities-----tough competition with other foreign languages}

Influenced by diversified language policy in international society, the Philippine language policy has opened up since 2008. In July 2009, the Philippine Education Ministry issued the 74th Act, prescribing the diversified mother-tongue based language education in the formal and informal education. The Act provides the advancement space as well as competition for many languages. As to SPFL, Chinese is facing competitions from Spanish, Japanese, French, Germany, which have 3531, 3020, 1112, and 583 followers respectively. ${ }^{5}$ Those are selective foreign languages in public schools and promoted by institutes like CI of each country, such as the Goethe Institute, Spanish Embassy, AECID, Japanese International Communication Fund and French Embassy in Manila, which are looking for cooperation with the Education Ministry of the Philippines and supporting courses opening and cultural activities. Moreover, as more Koreans migrated to the Philippines for inhabitation and travelling, teaching Korean as a foreign language is winning a strong momentum. As a result, foreign languages are in a wane-and-wax relation. Therefore, making use of the rise of "China Fever" and "Mandarin Fever" and giving support to the PVC in the Philippines will adequately tap the expansion space and potential of PVC.

\section{STRATEGIES OF THE POPULARIZATION OF MANDARIN CHINESE UNDER NEW SINO-PHILIPPINE RELATIONS}

Recent years, with the acceleration of the construction of "the Belt and Road Initiatives", China pushes forward the harmonious development and communication with neighboring countries with the concept of closeness, honest, benefit and tolerance in mind. The switch of Sino-Philippines relations is marked by the visit of Philippine president Rodrigo Duterte to China and signed 13 cooperative agreement and memorandum of understanding on economy, trade and etc. Therefore, the importance attached to the communication of the two countries, cultural power and the exploration of strategies of the PVC in the Philippines is in line with the mutual needs and long-term

\footnotetext{
${ }^{5}$ Department to Education, Republic of The Philippines,

http://www.deped.gov.ph/press-releases/

deped-enhances-learners\%E2\%80\%99-foreign-language-skills-throughspecial-program-foreign,2017-05-20.
} 
interests and is one of the effective approaches to opening and development and in-depth cooperation.

\section{A. Construction of an all-round, multi-layer and wide-} ranging PVC pattern, encouragement of the participation of enterprise and society

During president Duterte' visit to China, the Memos of understanding signed by China and the Philippines amounted to 24 billion US dollars. China and the Philippines agreed to build China Industry Park in the Philippines, with more Chinese companies settled in the Philippines or expand the branches in the Philippines encouraged by policies and more communication between China and the Philippine enterprises will boost the demand of learning Chinese. Therefore, we should make use of the opportunity of deepening economic cooperation to create conditions for the PMC in the Philippines and build up all-round patterns on the basis of its own CLE institutes and the international popularization of Chinese culture. Local overseas Chinese and China's enterprises should be encouraged to provide employment for graduates of Chinese major through talents transmission channels between schools and employers besides the funding of scholarships. Language institutes should carry out the training of targeted talents with Chinese language specialties. While fortify the practical value and economic output of Chinese language skills and the reputation and integration of enterprises in local areas, we can reduce the human resource cost for companies, which otherwise have to employ highly-paid employees from China, and achieve win-win effect for education institutes and enterprises. Those were also one of effective measures for the strategies of "the Road and the Belt Initiatives".

\section{B. Strengthening the construction of concrete promotion strategies, cementing the integration of Mandarin Chinese and Chinese culture with local culture.}

Because the rise of the attention on Mandarin Chinese teaching and learning, CLE has made "to foster Philippine citizens mastering Chinese culture and language" ${ }^{6}$ as its aim, PMC should adapt detailed methodologies to be used to the new Sino-Philippine relations and language demand based on local culture characteristics from the China state strategies and the compatibility of cultural diplomacy.

In the aspect of CLE, practical courses should be added in addition to basic training courses such as business Chinese, engineering Chinese, scientific Chinese, travelling Chinese, legal Chinese and so on. Localized textbooks are to be compiled for the Philippines. A successful example is Chinese for Filipinos, which was compiled by the Philippine Center for Chinese Education on the basis of the CLE syllabus for the tenyear primary and middle school education. The set of textbooks is made up of 12 parts, with conversation the main theme, targeted at cultivating the Chinese language competence in listening and speaking in daily life."7 . The set of textbooks is a

\footnotetext{
${ }^{6}$ Yan Changcheng, Huang Duanming, The Evolution of Chinese Education in the Philippines[A].Comprehensive Yearbook of Chinese Education in the Philippines(1995-2004)[M] Manila: Philippine Chinese Education Research Center 2008:118.(In Chinese)

${ }^{7}$ Philippine Chinese Education Research Center,

http://www.pcerc.org/Others/Huayi_bks/huayi.htm,2017-05-20
}

meaningful try of the Philippine Center for Chinese Language Education and worthy of being learned from for the compilation of localized Philippine textbooks.

Comparing with other Southeast Asia countries, the Philippines has a long history of Chinese promotion, dating back to the 16th century, when China's merchants settled down in the Philippines by ship. Because they benefit a lot from business in the Philippines, they are happy to give back to the locals. The Chinatown in Manila is the main gather up for the Philippine Chinese and a famous small commodity collection and distribution center. As the Philippine Chinese maintain cultural traditions and customs, Chinatown is the all the interpretation of China's culture. Therefore, we should pay attention to contemporary China's culture when promoting traditional culture to give opportunity to local people to get an understanding of a new China and China Dream. We should also attach importance to the culture communication and introduce contemporary enterprise culture, the rule of law, legal culture, household culture and harmonious concept proposed in the "the Road and the Belt Initiatives" to help local people get to know China and accept China and alleviate the threat, fear and hostility towards China due to long-term misunderstanding.

\section{The integration of domestic and international resources to strengthen the construction of the popularization of Mandarin Chinese in the Philippines.}

1) Positively support Chinese language education and the cultivating of local Chinese teachers.

As more and more Chinese migrated into the Philippines, more language carriers come up, less gap between the Philippine Chinese culture and China's culture and more influences of "instrumental Mandarin Chinese". Therefore, supporting the development of Chinese organizations and the CLE is of great significance, especially the standardized professionalized local Chinese teachers and management staff. First of all, according to the initiatives of the Philippine Center for the Chinese Education such as the "Blood Transfusion" and "Professionalized Plan", we should inject more funds for projects for teacher training and scholarships and encourage students studying in China to get degrees from the second major such as PE. Class, Business Chinese, Engineering, Transportation and continue their study career for Master and Doctor degrees in order to make themselves better professional teachers and qualified management staff. Faculty in the Philippines should also be recommended to study further (for bachelor's degree or higher) and continue the perfection of training, assessing, authentication and motivation coordinating the correspondent undergraduate certificate courses established by CLD department of Jinan University. At the same time teachers' salaries should be raised to prevent the loss of talents.

2) Making full use of the platform of the Confucius Institute.

So far as we know, there are four CIs settling in the Philippines, giving Chinese courses with flexible time, contents, format and language learners, which are a favorable complement for the current Philippine education system. CIs can provide high-end satisfying trainings for learners 
comparing with local CLE training institutes with professional teachers from China, sufficient Chinese education resources and international exchange platform. We should expand service areas of CI to the neighborhood besides schools, government agencies, enterprises and organizations with more popularized and practical language courses.

On the other hand, the extension of CI services should provide culture exchanges and development. It's necessary to set up the "exit" for Chinese as well as the "entrance" for the Philippine cultures. With the warming-up of Sino-Philippine relations, much more cooperation have begun in all fields, the evidence of which is the eagering enterprises from the Philippines. CIS should act as the information center for the entry of the Philippine culture into China and provide information on culture, economy, education and law for the local Philippine enterprises and translation services. An effective fruit of the $\mathrm{CI}$ as the communication and cooperation agent has already folded out. Philippine publisher TAWID as the first folk media ready to go into China's market with readings for children has contacted the $\mathrm{CI}$ at the Philippine University for translation and information support.

\section{The full use of new media.}

Hanban has proposed the transformation of the papertextbooks and face-to-face teachings into the diversified multimedia network courses. The introduction of the Internet into the information communication bring in multiple possibilities in the information era. The web tendency reports issued by the world-famous social media management platform Hootsuite and the British Consultancy Co. Ltd We Are Social shows that the average time the Philippines spend on Facebook and twitter is 4hours and 17minutes, ranking first in the world. ${ }^{8}$ Furthermore, many Philippines are very familiar with the on-line language learning and teaching system. Therefore, the advantages of new media such as website building, the interactive Chinese center on Facebook should be explored to integrate into the local Philippine neighborhoods. Other multimedia software should be adopted into the creation of vivid, interesting and easy-going virtue language environment through the development of dictionaries, cellphone apps.

\section{CONCLUSION}

To sum up, the PMC in the Philippines as one of the important front in the Southeast Asia has a long history though encountering obstacles at times but still a bright future. In the new era of Sino-Philippine relations, the PMC is facing a new opportunity when the pragmatic values of Chinese in the Philippines increase a lot. The content, format, subject and method of PMC should be innovated with the call of the era. To be sure, the PMC will be taking a new step with our persistence and advances with "the Road and the Belt".

\section{REFERENCES}

[1] Zheng Tongtao, Jiang Youjing and Chen Ronglan ,“The Annual Report of Teaching Chinese as a Second Language in Southeast Asian(II) "[J],

${ }^{8}$ Guangming Daily, http://news.gmw.cn/2017-02/04/content_23626479.htm [DB/OL], 2017-05-20
Overseas Chinese Education. Xiamen, General serials 71,pp.124-129, No.2,2014.(In Chinese)

[2] ELLEN H.PALANCA,A, "Comparative Study of Chinese Education in the Philippines and Malaysia”[J], ASIAN STUDIES, pp.3-10,Nov 2002.

[3] Zhuang Guotu, Chen huayue, The History of the Chinese in the Philippines[M], Xiamen: Xiamen University Press, pp.1-122, 2012. (In Chinese)

[4] Yan Changcheng, Huang Duanming, The Evolution of Chinese Education in the Philippines[A], Comprehensive Yearbook of Chinese Education in the Philippines(1995-2004)[M], Manila: Philippine Chinese Education Research Center , pp. 116-120, 2008. (In Chinese)

[5] Zhang Chun, Xu Yanfei, "Language Resources and Language Economy in the Philippines”[M], J. of Wuhan Uni. of Sci. \& Tech. (Social Science Edition), Wuhan, pp. 460-461, August, 2015. (In Chinese)

[6] Dai Jiayi,A Research on Development of Chinese Education in the Philippines[D], Guilin: Guangxi Normal University , pp. 9-41, 2010. (In Chinese) 